\title{
The vital role of organizations in protecting climate and nature
}

\author{
Combatting climate and ecological change is often framed as the responsibility of either individuals or national \\ governments. Organizations, which are intermediate in size and influence, have enormous potential to deliver \\ effective policies. As an illustration, we consider approaches taken by UK organizations to reduce meat \\ consumption.
}

\section{Emma E. Garnett and Andrew Balmford}

$\mathrm{L}$ imiting global heating to $1.5^{\circ} \mathrm{C}$ and protecting biodiversity will require action from all sectors and across society. Environmental action is often framed as the responsibility of either individuals or national governments (sometimes via international agreements). Particularly from wealthier individuals, some personal actions - reducing air and car travel, having fewer children and moving to more plant-based diets - can substantially reduce greenhouse gas emissions and change social norms, but individual actions alone are not sufficient. Even with drastic changes to behaviour in response to the COVID-19 pandemic, fossil fuel emissions declined only by $6 \%$ in $2020^{1}$ and deforestation rates increased compared to 2019. Likewise, to date, current climate policies from governments would still lead to an estimated $2.7^{\circ} \mathrm{C}$ of warming by $2100^{2}$. Greta Thunberg in a speech in 2019 observed: "And yes, I know we need a system change rather than individual change. But you cannot have one without the other." Both individual and system change are clearly needed; action at the level of organizations that are intermediate in size and influence can be instrumental in catalysing behaviour change in both.

Organizations (defined broadly here as, for example, businesses, nongovernmental organizations (NGOs), charities, universities, schools, hospitals, and local and regional governments) have long been recognized as having a vital role in reducing environmental damage. They make decisions that influence the choices available for hundreds, and sometimes thousands, of citizens. Sustainability decisions taken by organizations are therefore much more powerful and influential than actions taken by one individual alone. Although organizations (generally) have less power than national governments, they can also (generally) act more quickly and ambitiously. Most organizations need to

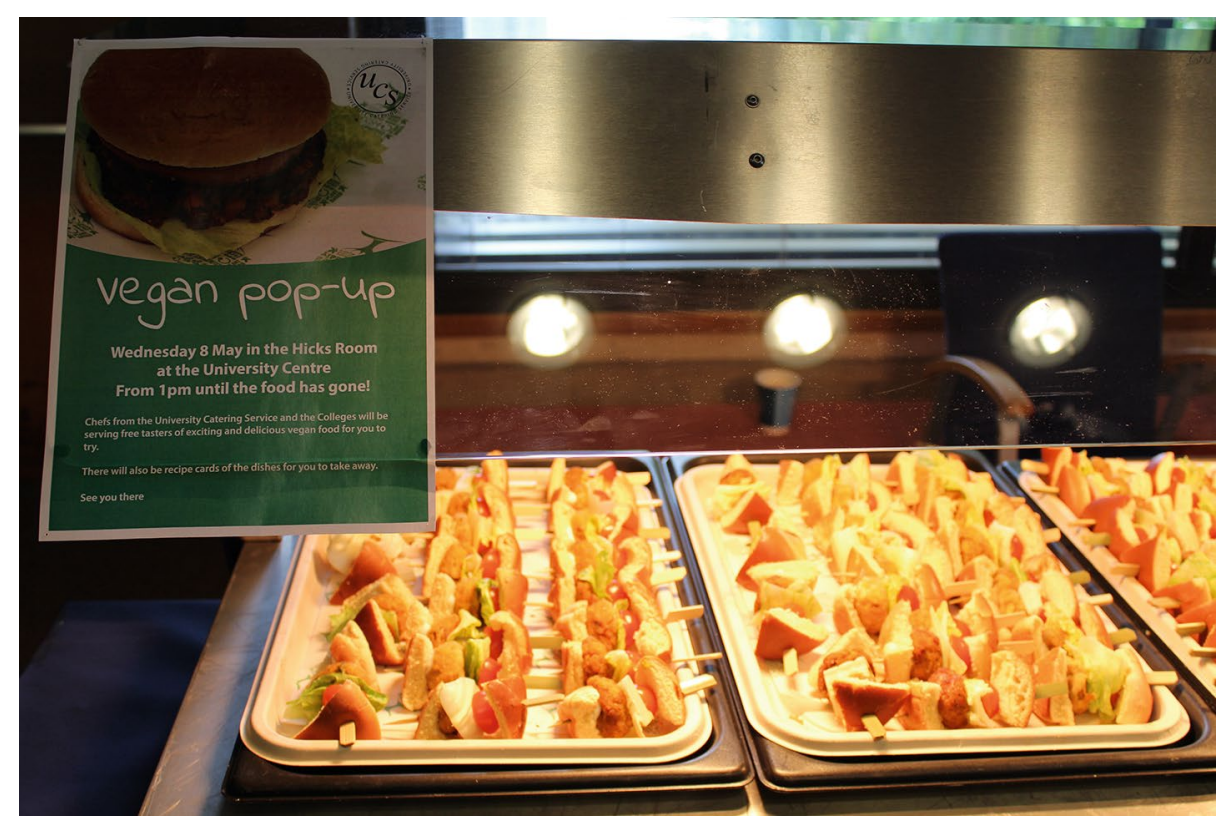

Fig. 1 | Example of an organization taking a role in climate action. The free vegan pop-up hosted by the University Catering Service. Photograph by University of Cambridge Estates Division.

consider expenditure, but (democratic, subnational government institutions aside) they do not need to consider electability. While current government policies do constrain organizations' ability to operate sustainably and changes to national policies are vital, organizations can often already make changes and by doing so shift social norms and put pressure on governments to do more. NGO campaigns to make the practices of businesses more sustainable - particularly around sourcing, supply chains and deforestation - have long had an important and recognized role in scrutinizing corporations and driving change. However, arguably, there has been far less focus on pushing for internal changes within NGOs themselves (and other noncorporate organizations) on key aspects of their operations, from food procurement to investments to transport.

As an illustration of intermediate-level efforts to achieve societally beneficial change, we consider shifts in wealthier societies towards more plant-based diets, and describe approaches taken by organizations to reduce meat consumption. We use the UK as a representative example of a wealthy country with high consumption of animal products.

\section{Climate change and meat reduction Agriculture has transformed the planet more than any other human activity, and livestock farming has particularly high environmental impacts. Even the lowest-impact meat, fish and dairy foods tend to have higher carbon footprints}


than the highest-impact plant-derived foods. The UK government's independent National Food Strategy has called for a $30 \%$ reduction in meat consumption over 10 years $^{3}$. More strikingly, the Planetary Health Diet - recommended for feeding 10 billion people healthily and sustainably - includes an average of $16 \mathrm{~kg}$ of meat, 10 $\mathrm{kg}$ of seafood and $91 \mathrm{~kg}$ of milk (including milk equivalents of dairy products) per person per year ${ }^{4}$. However current mean UK consumption (including retail and household-level food waste) of meat, fish and milk is $80 \mathrm{~kg}, 20 \mathrm{~kg}$ and $224 \mathrm{~kg}$, respectively ${ }^{5}$. In theory, all British citizens could individually reduce their meat, fish and dairy consumption to levels compatible with the Planetary Health Diet. However, we suspect that - provided that these products remain relatively cheap, readily available and embedded into British culture - such an enormous shift is highly unlikely through individual-level efforts alone.

There are many national policies that could aid in the transition to more plant-based diets, such as redirecting farming subsidies towards arable and horticulture production, introducing a food-industry carbon tax, mandating public food sector outlets to include more vegan and vegetarian options ${ }^{6}$ and including plant-based cooking skills on the national curriculum. However, successive governments in the UK and elsewhere appear reluctant to align their policies with their own stated objectives on reducing meat consumption. This may be due to opposition from the livestock industry and a fear that such policies would be perceived as overly interventionist. Whatever the reason, the evidence to date suggests that many governments seem unwilling to take sufficiently bold action to lower meat consumption to meet even existing commitments to emissions reduction. But can organizations help to meet these shortfalls?

\section{Organizations as sustainable food policy-makers}

It is important to remember that decision-makers in the retail and catering sectors can act as key policy-makers for transitions to sustainable diets. By curating menus, designing supermarket layouts and choosing which foods to source, when and from where, they set the parameters that affect how hundreds of customers and diners choose what to buy and eat. Indeed, animal advocacy charities - including Humane Society International and PETA (People for the Ethical Treatment of Animals) - have pivoted to providing vegan training for chefs and working with caterers, rather than focusing on campaigns promoting veganism to individual citizens (C. Tarry, personal communication) As well as direct effects, positive spill-overs are possible: individuals might find it easier to change their own domestic dietary habits if they have experienced good vegetarian and vegan food in an organizational setting, such as a workplace cafeteria.

In the private sector, sales of meat and dairy alternatives grew by almost $10 \%$ per year between 2010 and 2020 in the EU and UK, though they remain a small part of the overall market at $0.7 \%$ for meat and $2.5 \%$ for dairy ${ }^{7}$. In the UK, most pizza chains now offer pizza with vegan cheese, and many high street coffee chains offer a variety of plant-based milks. Some supermarkets have trialled placing meat alternatives in meat aisles to encourage 'flexitarian' shopping habits ${ }^{8}$. One supermarket aims to increase sales in meat alternatives by $300 \%$ by $2025^{9}$ and others have committed to reducing the cost of their own-brand plant-based products to match the price of their meat or dairy counterparts ${ }^{10}$. However, no British supermarkets have publicly available targets to reduce meat sales ${ }^{9}$. If meat alternatives do not reduce meat consumption and instead displace whole grains, legumes and vegetable consumption, this could have detrimental effects on both health and the environment. It is clearly more important to examine whether organizations have reduced meat and dairy sales, rather than simply increased sales of meat alternatives.

In contrast to the private sector, some public sector organizations have explicit meat and dairy reduction targets. Public Sector Catering - which represents the food service in the public sector in the UK, including outlets in schools, hospitals, care homes and prisons - announced their outlets will serve $20 \%$ less meat ( 9 million $\mathrm{kg}$; equivalent to 45,000 cows or 16 million chickens) to meet the recommendations of the UK's Committee on Climate Change, although they have not specified by when (http://20percentlessmeat.co.uk) ${ }^{11}$. One quarter of the population of the UK eats meals from these caterers so this change will affect millions of people. The Eating Better Alliance, of over 60 organizations, is campaigning for halving meat and dairy consumption in the UK by $2030^{\circ}$. At the regional government level, mayors from 14 cities in the UK and worldwide (including London, Tokyo, Lima and Los Angeles) have signed up to the Good Food Cities Declaration, pledging to reduce meat served at public institutions to align with the Planetary Health Diet ${ }^{12}$, which in the UK would involve an approximately $75 \%$ reduction in meat served - by some margin the most ambitious of the schemes outlined here.

\section{Delivering change in practice}

In 2016, the Cambridge University Catering Service (which runs 14 cafeterias across the university) introduced an ambitious 'Sustainable Food Policy'. Its four main pillars were taking ruminant meat off the menu, sourcing sustainable fish, reducing food waste, and promoting and increasing provision of vegetarian and vegan food ${ }^{13}$. To encourage students to try vegan options, free samples were provided from a vegan pop-up van and chefs received training in vegan cuisine (Fig. 1). In 2019, the University Catering Service reported that since the introduction of the Sustainable Food Policy, per kg of food purchased, greenhouse gas emissions decreased by $33 \%$, land-use decreased by $28 \%$ and meat purchases declined by $37 \%$ : gross profits increased by $2 \%{ }^{13}$. The Sustainable Food Policy has influenced the choices of thousands of customers and the report's publication made UK national news ${ }^{14}$. Cambridge's Sustainable Food Policy has won national catering awards and was a finalist in a global competition recognizing transformative behavioural approaches to combatting climate change ${ }^{13}$. Other organizations interested in reducing the environmental impact of their food procurement have approached Cambridge University Catering Service for advice, and are adopting similar practices.

\section{Organizations as catalysts of change}

There are of course many other actions that organizations - in almost all sectors - can undertake to benefit biodiversity and the climate. Interventions to reduce emissions from transport, for example, can include mandating remote video meetings instead of flying, installing electric-car charging points, subsidizing public transport for employees and providing safe bicycle storage and repair facilities at work. Many organizations have started redirecting employee pension schemes away from investments in the fossil fuel sector and shifted to buying energy only from renewable energy companies. Organizations can choose to manage any green space they oversee in ways that benefit nature: retaining dead trees, creating small wetlands, planting wildflowers and minimizing mowing and pesticide use.

It is unrealistic - and, given current price structures, choices and infrastructure constraints, also unreasonable - to expect individuals acting alone to substantially mitigate the climate and extinction crises. Current government policies and targets are insufficient to limit climate change. We 
argue that interventions by organizations, as a third group of intermediate-level actors, will be pivotal in bridging these shortfalls. As well as direct effects, more sustainable practices adopted by organizations can lead to positive spill-over effects and help to shift wider social norms, increasing the scale of what governments and individuals perceive as feasible. Activists campaigning for change could have more success by focusing on decision-makers in organizations rather than trying to persuade individuals one at a time to change their behaviour. Activism directed at governments is also essential, and organizational change at subnational levels can make national change more likely. For example, the Extinction Rebellion climate protests called on the UK to declare a climate and ecological emergency in 2018 : dozens of local councils across the UK did so, putting pressure on the UK government, which passed the declaration in May 2019. Furthermore, analyses have found that city and regional climate commitments are generally more ambitious than national commitments and could reduce greenhouse gas emissions by a further $3.8-5.5 \%{ }^{15}$, which will hopefully accelerate national government action.

Realizing the potential of organizations necessitates expanding our view of who is considered a policy-maker. For many people, the term conjures up images of civil servants and parliaments in nations' capitals. But we would argue that anyone who makes decisions that other people (beyond their immediate household) then abide by - for example, on food procurement, heating settings in a building or company transport policies - is in effect a policy-maker. Just as acting on climate and ecological emergencies requires actions from all sectors of society (individuals, organizations and national governments), so too we will need a diverse and wide range of policy-makers to bring about the scale of change needed.

\section{Emma E. Garnett (DiD) ${ }^{1,2 \bowtie}$ and}

Andrew Balmford ${ }^{2}$

${ }^{1}$ Cambridge Institute for Sustainability Leadership, University of Cambridge, Cambridge, UK. ${ }^{2}$ Conservation Science Group, Department of Zoology, University of Cambridge, Cambridge, UK.

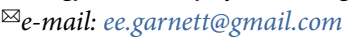

Published online: 3 January 2022

https://doi.org/10.1038/s41562-021-01260-z

References

1. Tollefson, J. Nature 589, 343 (2021).

2. Climate Action Tracker. The CAT thermometer.

climateactiontracker.org, https://go.nature.com/3crR95J (2021).
3. Dimbleby, H. National food strategy independent review: the plan. nationalfoodstrategy.org, https://go.nature.com $/ 3 \mathrm{HzWpmd}$ (2021).

4. Willett, W. et al. Lancet 393, 447-492 (2019).

5. Ritchie, H. \& Roser, M. Meat and dairy production. OurWorldInData.org, https://go.nature.com/3kUte3B (2017).

6. Marteau, T. M., Chater, N. \& Garnett, E. E. BMJ 375, n2293 (2021).

7. Geijer, T. \& Gammoudy, A. Growth of meat and dairy alternatives is stirring up the European food industry. think.ing.com, https:// go.nature.com/3FsQKws (2020).

8. Piernas, C. et al. PLoS Med. 18, e1003715 (2021).

9. Feedback. Meating the climate challenge. feedbackglobal.org, https://go.nature.com/3oI4kW6 (2021).

10. Wood, Z. Co-op slashes the price of plant-based food in quest for net zero emissions. theguardian.com, https://go.nature. com/3nyIuFg (5 May 2021).

11. Committee on Climate Change. Land use: policies for a net zero UK. theccc.org, https://go.nature.com/3FwUNYF (2020).

12. C40 Cities. 14 cities commit to sustainable food policies that will address the global climate emergency. $c 40$. rg, https://go.nature. com/3HCVW2H (8 October 2019).

13. University Catering Service. Our sustainable food journey. environment.admin.cam.ac.uk, https://go.nature.com/3csDIm2 (2019).

14. BBC. University of Cambridge: removing meat 'cut carbon emissions. bbc.co.uk, https://go.nature.com/3nwQN4n (10 September 2019).

15. Kuramochi, T. et al. Clim. Policy 20, 275-291 (2020).

Acknowledgements

We thank T. Marteau, C. Sandbrook, C. Tayleur and P.

Lumb for their comments on this manuscript.

Competing interests

The authors declare no competing interests.

Additional information

Peer review information Nature Human Behaviour thanks Tom MacMillan and the other, anonymous, reviewer(s) for their contribution to the peer review of this work. 